\title{
VACIADO DE EDIFICIOS CONSERVANDO LA FACHADA
}

\author{
(THE GUTTIN OF BUILDINGS WHILE MAINTAINING THE FACADE)
}

\section{Santiago González Rodríguez; Dr. Arquitecto}

Profesor de Mecánica del Suelo y Cimentaciones

Especiales de la E.T.S.A.M.

Arquitecto Jefe de la Sección de Edificación

Deficiente de la Gerencia Municipal de Urbanismo

(Ayuntamiento de Madrid)

$105-4$

\section{RESUMEN}

Bajo el título "Vaciado de edificios conservando la fachada», se presenta este trabajo que recoge, no sólo el aspecto técnico de la reestructuración de edificios, sino también aspectos legales sobre la rehabilitación en general y su problemática.

Tras un breve comentario sobre la legislación vigente, se entra en materia sobre las ayudas a la rehabilitación en la búsqueda de soluciones que puedan dotar de eficacia a los actos administrativos orientados hacia la finalidad de conservar el patrimonio artístico y cultural. Se analizan las normas urbanísticas de protección y la Ordenanza Reguladora Municipal de Ayudas a la Rehabilitación, donde se vislumbra una voluntad del Ayuntamiento de Madrid y una toma de conciencia del problema, arbitrando, aunque todavía tímidamente, unas subvenciones y ayudas financieras para la conservación del patrimonio urbano.

Es importante destacar la distinción que se hace entre la conservación normal $u$ «ordinaria» del edificio y la conservación singular o "extraordinaria», por cuanto afecta a las obligaciones de la propiedad en tanto no se rebase el límite del deber de conservación que le corresponde, así como a la Administración en cuanto a la obligación que le incumbe de prestar la ayuda necesaria.

En cuanto a la parte técnica, sin pretender ser riguroso, se expone un método práctico y sencillo para el mantenimiento provisional de las fachadas en tanto se procede a la sustitución del interior del edificio. Aparte de unas recomendaciones sobre las precauciones que deben tomarse y de la descripción del sistema de apuntalamiento, se dan los criterios de cálculo de la estructura tubular metálica, la normativa que es de aplicación y los costes aproximados por metro cuadrado.

\section{SUMMARY}

This study, which is presented under the heading «The gutting of buildings while maintaining the façade», takes up not only the technical aspect of restructuring buildings, but also the legal aspects concerning rehabilitation and its problems.

Following a brief commentary on prevailing legislation, it goes into rehabilitation in search of solutions which might lend more effectiveness to administrative work oriented towards the aim of keeping up artistic and cultural heritage. Urban standards of protection and the Municipal Bylaws for the Control of Rehabilitation Assistance are analysed, in which one begins to see good intentions on the part of the Madrid City Council and an awareness of the problem, raising grants and financial aid, though still somewhat timidly, for the upkeep of urban patrimony.

It is important to stress the distinction which is made between normal or 'ordinary' upkeep of a building and outstanding or 'extraordinary' upkeep in as much as it affects the obligations pertaining to property, as long as it does not exceed the limit of the obligation of maintenance which corresponds to it, as well as affecting the Government with respect to the obligation incumbent on it to provide the necessary assistance.

Regarding the technical aspect, without trying to be rigorous, a simple and practical method is expounded for the temporary maintenance of façades while going ahead with the substitution of the interior of the building. Besides the recommendations on the precautions that should be taken and the description of the shoring-up system, the criteria for calculating the tubular metallic structure, the regulations to be applied and the approximate costs per square metre are provided.

\section{INTRODUCCION}

La rehabilitación de edificios es una de las actividades dentro de la edificación que está adquiriendo cada dia mayor importancia. Razones de tipo cultural como es la conservación de edificios y conjuntos histórico-artisticos en sus diferentes categorias, y razones también de carácter social y económico se imponen para proteger el patrimonio urbano.

Recuperar un edificio no siempre resulta económi$\mathrm{co}$, pues en algunos casos posiblemente sea más costoso rehabilitar lo edificado que derribarlo $y$ construir de nuevo, todo depende del grado de deterioro en que se encuentre. También depende de 


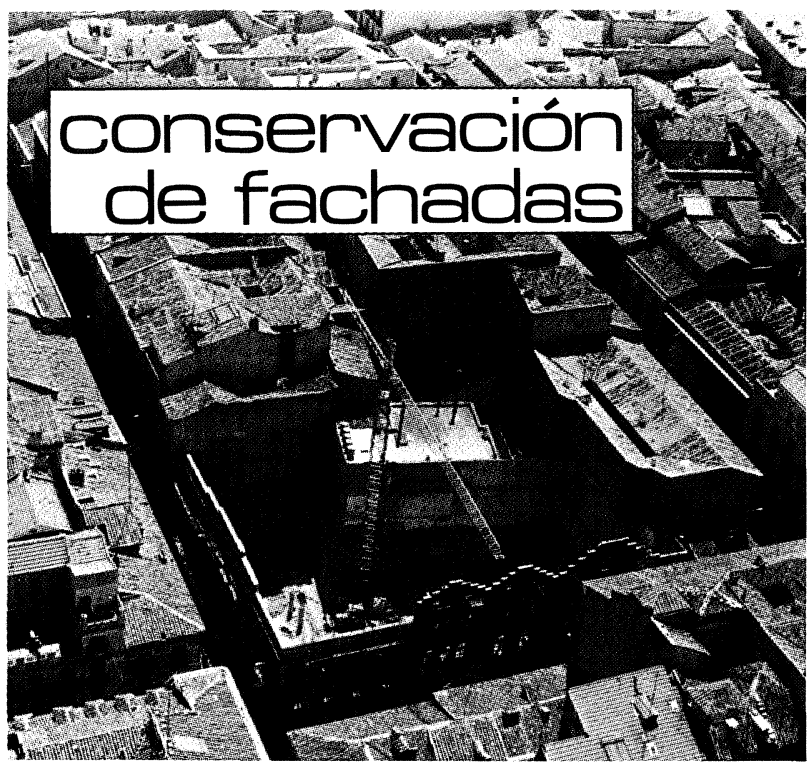

la superficie total edificable que autoricen las ordenanzas municipales, el que una u otra operación sea más o menos rentable.

En cualquier caso, la rehabilitación o reestructuración de edificios, es a largo plazo ventajosa para la economía de la ciudad. El abandono de las obras de conservación ha hecho que el centro o casco antiguo de las ciudades y también el antiguo ensanche se deteriore; las viviendas no son confortables, en muchos casos son antihigiénicas $y$ en algunos inseguras, mientras tanto se construyen grandes urbanizaciones con edificios de viviendas $y$ sus correspondientes equipamientos en la periferia y pueblos limitrofes. Ello comporta importantes gastos de urbanización e infraestructura, la ampliación de redes de abastecimiento y suministro de servicios con los consiguientes gastos de mantenimiento que redundan en la economía de la ciudad.

Independientemente de las cuestiones técnicas y económicas, el mantenimiento de las fachadas es una de las condiciones impuestas por los Planes Especiales de Protección Histórico Artística y posiblemente la que se da con más frecuencia entre los edificios protegidos.

Asi en el Plan Especial de la Villa de Madrid y dentro del "nivel de protección estructural" se permiten, aunque con carácter no preferente, las obras de reestructuración parcial o total, llegando en su grado máximo a las de vaciado del edificio conservando la fachada. En algunos casos, dentro del "nivel de protección ambiental" también puede imponerse la conservación de la fachada.

Generalmente las fachadas de los edificios son la parte mejor conservada debido también a su mejor calidad constructiva. Se diferencian del resto del edificio por sus materiales más nobles, su robustez y su más cuidada ejecución.
Debido a la gran cantidad de edificios protegidos en los niveles "estructural" y "ambiental" llegamos, en un buen número de casos, a la necesidad actual de tener que demoler el interior de un edificio, incluso a veces con vaciado del solar para construir sótanos de aparcamiento, manteniendo en pie y conservando la fachada.

\section{PROTECCION Y CONSERVACION DEL PATRIMONIO URBANO}

\subsection{LEGISLACION}

- Ley del Tesoro Artístico (13-5-1933).

- Ley sobre Régimen del Suelo y Ordenación Urbana (Texto Refundido del 9-4-1976)

- Reglamento de Disciplina Urbanística (23-6-1978)

- Ordenanza sobre el deber de Conservación y Estado Ruinoso de las Edificaciones (Ayuntamiento de Madrid 26-10-1979)

- Plan Especial de Protección y Conservación de Edificios y Conjuntos de Interés Histórico Artístico de la Villa de Madrid (Aprobado definitivamente por COPLACO el 23-10-80)

- Ordenanza Reguladora de la Ayuda Municipal a la Rehabilitación de Edificios Residenciales en el ámbito del Plan Especial de la Villa de Madrid (Septiembre de 1982)

- Real Decreto 2329/83 de 28 de julio sobre Protección a la Rehabilitación del Patrimonio Residencial y Urbano.

\subsection{COMENTARIO}

A pesar de la abundante legislación dictada en materia de protección de monumentos históricoartísticos encabezada por la Ley del Tesoro Artístico Nacional de 13 de mayo de 1933, y de que la Ley de Régimen del Suelo y Ordenación Urbana de 12 de mayo de 1956 introdujo la posibilidad de formación de Planes Especiales para proteger los valores artísticos, históricos, culturales, turisticos o simplemente típicos de nuestras ciudades, el camino emprendido ha permanecido prácticamente dormido durante estos años. Cobra hoy actualidad, coincidiendo la nueva legalidad urbanistica y su desarrollo reglamentario con un importante movimiento sociológico de recuperación de la ciudad y mantenimiento de sus caracteristicas tradicionales.

Este sentimiento colectivo ha tenido su reflejo en el texto de la nueva Constitución de 1978, cuyo Artículo 46 dice:

"Los poderes públicos garantizarán la conservación y promoverán el enriquecimiento del patri- 
monio histórico, cultural y artístico de los bienes de España y de los bienes que lo integran, cualquiera que sea su régimen juridico y titularidad. La Ley Penal sancionará los atentados contra este patrimonio."

La conservación del patrimonio cultural ha pasado, pues, de ser una "competencia sectorial" encomendada tradicionalmente a la Dirección General de Bellas Artes, a ser una actuación de todos los poderes públicos en sus distintas demarcaciones territoriales, en donde está justificada la intervención de los Ayuntamientos, Diputaciones y demás autoridades urbanisticas.

Dentro del marco de la legislación del Tesoro Artístico, se distingue el "Catálogo de Monumentos Provinciales y Locales" creado por Decreto de 22-7-58, que atribuye la catalogación y conservación de monumentos de interés local a los Ayuntamientos y Diputaciones.

Por otro lado, la legislación urbanística (Ley de Régimen del Suelo) confiere a los Ayuntamientos y Diputaciones la posibilidad de formación de Planes Especiales para la protección de los valores histórico-artísticos.

Ambos cauces de protección, el del Tesoro Artístico y el Urbanístico se presentan como alternativa de elección de los Ayuntamientos para abordar el mantenimiento de los valores culturales de la ciudad. Ambos persiguen el mismo fin, producen similares limitaciones en el patrimonio del administrado y contienen a cambio unas previsiones sobre la asistencia y cooperación de la Administración para el logro de dichos fines.

El precepto constitucional ha venido a aunar las distintas vias del ordenamiento juridico, y a reforzar la intervención de los poderes públicos, garantizando al mismo tiempo la "igualdad ante la ley" (Art. 14), la "igualdad de trato ante las cargas públicas" (Art. 31) y el reconocimiento de una propiedad privada de la que unadie podrá ser desposeido sino mediante la correspondiente indemnización y de conformidad con lo dispuesto en las Leyes" (Art. 33).

Por lo tanto, un mayor rigor en la aplicación de los distintos cauces de protección no puede suponer un mayor sacrificio económico para los administrados o un desigual trato y participación en la "carga pública". Sin embargo, la falta de un estudio económico financiero y la indefinición de "en qué consiste" la asistencia y cooperación de la Administración para el fomento de la conservación de edificios protegidos, han hecho ineficaces las medidas de recuperación y conservación pretendidas.

En Madrid, por ejemplo, la reducción de edificabilidad impuesta por la modificación de las Orde- nanzas, el Plan Especial Villa de Madrid y la revisión del Plan General con una mayor limitación en la superficie edificable, han influido más en el ánimo de los promotores hacia la rehabilitación que la propia ayuda económica y financiera de la Administración.

Es preciso pues, una mayor definición del objeto de la protección, de las limitaciones y condiciones que impone al derecho de propiedad, y sobre todo una mayor concreción y desarrollo de las ayudas a que se compromete la Administración, arbitrando unos remedios legales que permitan coordinar el fin protector público de los Planes Especiales con el principio de igualdad de trato de los administrados ante la Ley y ante las cargas públicas, por la doble vía de la uadecuada cooperación" administrativa en la conservación de los inmuebles, y la indemnización de la limitación dominical mediante la ordenación y ejecución del planeamiento, distribuyendo los beneficios y cargas mediante actuaciones urbanisticas como la reparcelación, compensación o expropiación. Ambas vias pueden encontrar respuesta en la actual mecánica de la vigente Ley del Suelo.

\section{AYUDAS A LA REHABILITACION}

La única referencia que hemos encontrado en la Ley en materia de ayudas a la rehabilitación y conservación de edificios, está contenida en el Artículo 182 de la Ley del Suelo que se transcribe:

1.-Los Ayuntamientos y, en su caso, las Diputaciones Provinciales de Urbanismo podrán también ordenar, por motivos de interés turístico o estético, la ejecución de obras de conservación y de reforma en fachadas o espacios visibles desde la vía pública, sin que estén previamente incluidas en Plan alguno de ordenación.

2.-Las obras se ejecutarán a costa de los propietarios si se contuvieren en el límite del deber de conservación que les corresponde, y con cargo a fondos de la Entidad que lo ordene cuando lo rebasaren para obtener mejoras de interés general.

3.-Los propietarios de bienes incluidos en los catálogos a que se refiere el artículo 25 podrán recabar, para conservarlos, la cooperación de los Ayuntamientos y Diputaciones, que la prestarán en condiciones adecuadas.

Cada elemento protegido debe ser, previamente, un elemento catalogado, por imponerlo así expresamente el Art. 25 de la Ley del Suelo para que sea eficaz la protección que los Planes Especiales dispensan.

No señala la Ley, ni tampoco el Reglamento, en qué debe consistir esta cooperación, quedando como un concepto indeterminado. En cambio su 
prestación resulta obligatoria según se desprende del carácter imperativo del precepto y deberá ser "adecuada" y congruente con el fin que persigue.

El Real Decreto $2329 / 83$ de 28 de julio sobre "Protección a la Rehabilitación del Patrimonio Residencial y Urbano", ha establecido, al fin, unos marcos financieros para las actuaciones privadas de rehabilitación en condiciones más ventajosas incluso que las aplicadas en la promoción de viviendas de Protección Oficial.

La Ordenanza Reguladora de la Ayuda Municipal a la Rehabilitación de Edificios Residenciales en el ámbito del Plan Especial Villa de Madrid, establece asimismo unas subvenciones y ayudas financieras, en determinadas condiciones.

En ambas disposiciones, aparte de la rehabilitación de edificios y viviendas, se incluyen las "Obras de interés arquitectónico, histórico o ambiental" de acuerdo con la aplicación del Art. 182 de la Ley del Suelo (Art. 5 del Real Decreto) 0 acordes con su nivel de protección en el P.E.V.M. (Artículo 5 de la Ordenanza Reguladora).

El Real Decreto 2329/83 establece:

Art. 5.2. Obras de interés arquitectónico, histórico o ambiental.

Se entenderán por tales las obras que fueran requeridas por los valores arquitectónicos, históricos o ambientales de los edificios, de acuerdo, en su caso, con las órdenes particulares de ejecución de obras que pudieran dictarse en aplicación del artículo 182 de la Ley del Suelo.

Art. 8. Regímenes de rehabilitación. -1. Las actuaciones de rehabilitación podrán efectuarse en tres regimenes distintos:

a) Rehabilitación libre.

b) Rehabilitación protegida de promoción privada.

c) Rehabilitación protegida de promoción pública.

2.-Las distintas Administraciones competentes para la promoción de viviendas podrán hacer uso de cualquiera de los tres regímenes y gestionar, en su caso, su acceso a las fuentes de financiación en las condiciones fijadas en este Real Decreto.

Art. 9. Beneficios. -1. Las actuaciones de rehabilitación podrán acogerse a los siguientes beneficios:

a) Préstamos con y sin interés.

b) Subvención parcial de los intereses devengados por los préstamos. c) Subvenciones personales.

d) Subvenciones especiales para la gestión de las actuaciones.

e) Exenciones y bonificaciones tributarias.

2.-Estos beneficios no podrán solicitarse cuando existieran préstamos pendientes de amortización concedidos para anteriores actuaciones de rehabilitación sobre la misma vivienda o edificio.

3.-Se exceptúan de esta limitación las actuaciones de rehabilitación que fueran efectuadas en cumplimiento de sentencia judicial o resolución administrativa.

La Ordenanza Reguladora Municipal establece:

Art. 5. Obras de interés arquitectónico, histórico o ambiental. Se incluirán en este concepto, a los efectos de la presente Ordenanza, las obras requeridas por los valores arquitectónicos, históricos o ambientales del edificio, acordes con su nivel de protección en el Plan Especial Villa de Madrid.

Estas obras podrán comprender, entre otros, los siguientes tipos de intervención:

a) La restitución de la organización tipológica originaria, o de elementos básicos de esa tipología.

b) La restitución de la composición arquitectónica exterior y, en particular, de la composición de fachadas de plantas bajas.

c) La reparación o reposición de elementos arquitectónicos o decorativos, tales como revocos, aleros, molduras, carpintería exterior, cerrajería, puertas de acceso y acabados de portales.

d) La adecuación de los frentes comerciales en plantas bajas a los valores del edificio o de su entorno.

Art. 10. Ayudas económicas especiales. Modalidades y requisitos generales para su concesión.

1.-Las ayudas económicas especiales adoptarán las siguientes modalidades:

a) Ayudas para obras de interés arquitectónico, histórico o ambiental. Se dirigirán a la realización de intervenciones con los contenidos a que se ha hecho referencia en el artículo $5 .^{\circ}$ de esta Ordenanza.

Su cuantía será del 20 por 100 del coste de las obras y no podrá exceder de la cifra de 250.000 pesetas por edificio, no incluyéndose en esta cifra las subvenciones dirigidas a la adecuación de 
frentes de locales comerciales o restitución de la composición de fachada en planta baja, que será, igualmente, de un 20 por 100 del coste de las obras, sin que esa cifra rebase las 100.000 pesetas por local.

Para acogerse a estas ayudas, es condición imprescindible que el edificio esté incluido en uno de los tres niveles de protección que establece el Plan Especial de la Villa de Madrid: Integral, Estructural y Ambiental.

Aunque esta Ordenanza Reguladora de Ayuda a la Rehabilitación ha constituido una medida profundamente innovadora, sin embargo, a lo largo del año 1983 no ha alcanzado unos resultados satisfactorios, debido sin duda a la cuantía insuficiente asignada a las subvenciones para incentivar actuaciones particulares, a las condiciones de orden técnico y constructivo exigidas para las obras, y a la complejidad de la tramitación y de las gestiones requeridas, dándose bastantes casos de realización de obras de rehabilitación sin solicitar ayuda o desistiendo de ella.

\section{Propuesta de modificación de la Ordenanza}

Actualmente está en estudio una modificación de la Ordenanza Reguladora, y para el caso de obras que nos interesa de mantenimiento de fachadas, se establecen unas modalidades con un incremento sustancial de las ayudas, haciendo una clara diferenciación entre obras de carácter ordinario y obras de carácter extraordinario.

Las primeras son las comprendidas dentro de los límites del deber de conservación que corresponde a la propiedad. Las segundas, son las que exceden de dichos limites.

A efectos de fijar el cómputo de las ayudas económicas, el presupuesto general, el carácter de las obras y el exceso sobre el deber de conservación, se transcribe el artículo 10 de la citada propuesta de Ordenanza Reguladora.

\section{Art. 10.-COMPUTO DE LAS AYUDAS ECONOMICAS}

1.- Cuando las ayudas económicas se dirigieran a la realización de obras, la cuantía de la subvención vendrá determinada por un porcentaje del presupuesto general de las mismas.

2.-Se entenderá como presupuesto general el integrado por las siguientes partidas:

\section{1. ${ }^{a}$ Presupuesto de ejecución material.}

2. ${ }^{a}$ Margen industrial 0 gastos de administración, según los casos, que se cifra, respecti- vamente, en el $17 \%$ y en el $8,5 \%$ del presupuesto de ejecución material.

3. ${ }^{a}$ Honorarios facultativos correspondientes, en su caso, a proyecto y dirección de las obras.

3. - Para el cómputo de la subvención, los Servicios Técnicos de la Gerencia Municipal de Urbanismo podrán establecer el presupuesto de ejecución material de las obras, cuando asi lo estimasen oportuno.

4.-El porcentaje que determinase la cuantía de la subvención se aplicará al menor de los siguientes presupuestos:

a) el que acompañe la solicitud de ayuda económica;

b) el que se presente después de la finalización de las obras, de acuerdo con lo requerido en esta Ordenanza;

c) el que, en su caso, correspondiese a la estimación del presupuesto de ejecución material realizada por los Servicios Técnicos de la Gerencia Municipal de Urbanismo.

5. - Cuando se hubiera concedido previamente ayuda económica municipal para la redacción del Proyecto de Ejecución, no se incluirá en el presupuesto general la cifra que correspondiera a los honorarios del citado Proyecto.

6.-A efectos de aplicación de ayudas económicas, se distinguirán en el Presupuesto General las partes que, en cada caso, correspondiesen a:

a) actuaciones de rehabilitación de elementos comunes de los edificios;

b) actuaciones de rehabilitación en elementos privativos de las viviendas;

c) obras de interés arquitectónico, histórico o ambiental de carácter ordinario, diferenciando las que afectasen a elementos comunes de los edificios, a elementos privativos de viviendas y a elementos privativos de locales;

d) obras de interés arquitectónico, histórico o ambiental de carácter extraordinario, con la misma diferenciación que se señala en el punto anterior.

Aunque este estudio de Modificación de la Ordenanza Reguladora no pasa de ser una propuesta, aún sin aprobar, no deja de ser un paso importante por la expectativa de futuro que representa.

Mientras tanto hemos de movernos dentro de la legislación urbanistica vigente. Conviene por tanto analizar los dos conceptos antes señalados, pues- 


\section{CUANTIA DE LAS SUBVENCIONES}

Obras de Interés Arquitectónico, Histórico o Ambiental de carácter ordinario.

Obras de Interés

Arquitectónico, Histórico o Ambiental de carácter extraordinario.

Edificios incluidos en
programas de
Adecuación
Arquitectónica.

Edificios no incluidos
en programas de
Adecuación
Arquitectónica.

Con orden de ejecución.

Sin orden de ejecución.
Para obras que afectan al edificio:

$50 \%$ del coste con un máximo de 750.000 pesetas por edificio.

Para obras que afecten a exteriores de locales en plantas bajas:

$50 \%$ del coste con un máximo de 250.000 pesetas por local.

Para obras que afecten al edificio:

$25 \%$ del coste con un máximo de 375.000 pesetas por edificio.

Para obras que afecten a exteriores de locales en plantas bajas:

$25 \%$ del coste con un máximo de 125.000 pesetas por local.

Cuantía equivalente a la parte del presupuesto que exceda del deber de conservación que corresponde a la propiedad, sin limitación máxima.

Cuantía equivalente a la parte del presupuesto que exceda del deber de conservación que corresponde a la propiedad, con limitación máxima de 1.500 .000 pesetas para obras que afecten al edificio y de 500.000 pesetas para elementos exteriores de locales en plantas bajas. to que apuntan remedios legales que permiten vincular el fin protector público del Plan Especial, con la actual mecánica de la Ley del Suelo relativa a la "adecuada cooperación" administrativa en la conservación de inmuebles a fin de hacer posible el principio de igualdad de trato de los administrados ante la ley y ante las cargas públicas, asumiendo los Organos gestores los excesos de costo o los costos adicionales motivados por el Plan.

\section{a) Conservación "ordinaria» del edificio}

El Art. 181 de la L.R.S. impone al propietario la obligación de mantener su finca en condiciones de seguridad, salubridad y ornato públicos. Los Ayuntamientos $y$, en su caso, los demás Organismos competentes ordenarán, de oficio o a instan- cia de cualquier interesado, la ejecución de las obras necesarias para conservar aquellas condiciones, sancionando el Reglamento de Disciplina Urbanistica en sus artículos 10 y siguientes su no realización.

Este régimen es prácticamente coincidente con el que se deriva de los Planes Especiales, siendo éstos los que deberán ser aplicables para los edificios protegidos, dada su especialidad, excluyendo al edificio catalogado, aún para su conservación "ordinaria", del régimen general.

La obligación normal de conservación impuesta por el Plan Especial, no implica, a primera vista, una carga específica para el administrado. Sin embargo, hay que tener en cuenta la utilidad pública singular que conlleva la conservación del inmueble catalogado, juntamente con la prohibición legal de 
demolerlo como forma de liberación para el propietario, es decir, el hecho de que el fin perseguido (cultural) es distinto del de la obligación general. Por otra parte, esta conservación puede ser más intensa, al tener que efectuarse en los términos del Plan, más exigentes de lo normal al imponer determinados materiales o técnicas más costosas. Por lo tanto, conviene distinguir entre edificios catalogados, o no, porque en el primer caso entramos en el Art. 182.3 de la Ley de R. del S.

El propietario del inmueble catalogado que se ve obligado a conservar, puede carecer de medios técnicos y económicos para el cumplimiento de su obligación normal, pero dada la especial transcendencia de la misma (elevada a "fin público" por el Plan), está facultado para solicitar la cooperación del Organo administrativo que promovió la protección. Una vez ejercitada esta opción por el administrado, el Organo vendrá obligado a cooperar en forma adecuada, por imperativo de la Ley (nótese el término "la prestarán»). La inactividad de la Administración ante la solicitud de ayuda, legitima la desobediencia a la orden de reparación, y por tanto no podrá imponer sanciones, ni acudir a la expropiación del edificio o de su fachada, ni a la ejecución sustitutoria con cargo al patrimonio del obligado.

\section{b) Conservación uextraordinaria» del edificio}

El Art. 182.1 y 2 de la L.R.S. va más allá de las obras de conservación normales al imponer incluso las de reforma de fachadas o espacios visibles desde la vía pública, es decir que sobrepasa conscientemente los limites normales de conservación para obtener "mejoras de interés general", tendentes más a la restauración que a la conservación, o por entrar en el campo de los edificios declarados en ruina. Se reconoce, en cambio, la regla general de que los fines públicos deben ser satisfechos con fondos también públicos.

Hay por tanto una clara distinción entre la obligación normal de conservar que corresponde a la propiedad y la extraordinaria conservación de edificios protegidos (en todo caso los edificios catalogados) garantizada por la Administración que se obliga a asumir el exceso de costos y a cooperar con los administrados.

El caso más claro se presenta en la declaración de ruina que regula el Art. 183 de la L.R.S. Con ella cesa la obligación de conservar y se establece un límite al deber de conservación, siendo la consecuencia lógica y los efectos jurídicos que produce, la demolición del edificio, lo cual no significa que haya de llegarse fatalmente a ella en todos los casos. La catalogación de un edificio o la inclusión dentro del Plan Especial, puede hacer perfectamente compatibles la situación de declara- ción de estado ruinoso y la de conservación derivada de sus cualidades histórico-artísticas, pudiendo la Administración evitar la demolición del edificio, pero sin poder imponer a su propietario la obligación de conservarlo a sus expensas, sino a cargo de la propia Administración que lo ordenare al haber considerado el edificio como un bien comunitario. Denegada la licencia de demolición de un edificio declarado en ruina, el propietario tiene derecho a solicitar la ayuda económica y técnica necesarias para conservarlo, y la Administración está obligada a prestarlas.

\section{TRAMITACION ADMINISTRATIVA}

La tramitación de los expedientes relativos a las ayudas a la rehabilitación de edificios, y las solicitudes de los beneficios establecidos en el Real Decreto $2329 / 83$ de 28 de julio, se formularán ante las Direcciones Provinciales del Ministerio de Obras Públicas y Urbanismo, de acuerdo con las normas establecidas en el mismo.

En cuanto a la ayuda municipal de edificios residenciales en el ámbito del P.E.V.M. se solicitará en la Gerencia Municipal de Urbanismo del Ayuntamiento de Madrid, simultáneamente con la licencia de obras y con arreglo a las normas establecidas en la Ordenanza Reguladora correspondiente.

\section{CONCLUSIONES}

De todo lo que antecede, se deduce el interés que tiene para los propietarios de fincas urbanas la cooperación o ayuda económica de la Administración con vistas a la rehabilitación de los edificios protegidos.

Por otra parte, esperar a que un edificio llegue al estado ruinoso, física o legalmente, para demolerlo y construir otro nuevo, no resulta ya tan ventajoso. El procedimiento de la declaración de ruina lleva una tramitación larga y el tiempo, cada día más, juega un papel importante. Si además, hay que ajustarse a las Ordenanzas en vigor, cada vez más restrictivas, resulta que es preferible acometer las obras de rehabilitación que permiten mantener, al menos, el volumen existente.

Así, en Madrid, con la modificación de las Ordenanzas Municipales del año 1980, se redujo la edificabilidad al suprimir una planta y aumentar las dimensiones de los patios. Actualmente, con la revisión del Plan General, se disminuye otra planta en un buen número de casos y se reduce la ocupación y volumen con una mayor limitación del fondo edificable, lo cual supone en el periodo de cuatro años una disminución de la superficie edificable de un 30 a un $40 \%$.

El Plan General de Ordenación Urbana de Madrid, sin duda, ha venido en apoyo del Plan Especial, 
integrando éste en aquél a fin de potenciarlo con miras a fomentar las obras de rehabilitación.

REFERENCIA: Algunos de los aspectos legales expuestos se han tomado del texto "REFLEXIONES SOBRE LA PROTECCION DEL PATRIMONIO CULTURAL INMOBILIARIO MEDIANTE PLANES DE URBANISMO", de César-Javier Sanz-Pastor. Comunicación presentada al I CONGRESO IBEROAMERICANO DE URBANISMO - SEVILLA 84, que versó sobre el tema de CONSERVACION Y REHABILITACION DE CENTROS URBANOS.

\section{MANTENIMIENTO DE FACHADAS. SOLUCIONES TECNICAS}

Como ya se ha dicho anteriormente, el Plan Especial de la Villa de Madrid establece tres niveles de protección y según la calificación del edificio, dentro de ellos, se pueden hacer determinada clase de obras, con carácter preferente o no preferente. Entre esa clase de obras están las de reestructuración parcial o total, pudiendo llegar en su grado máximo a las de vaciado del edificio manteniendo la fachada.

Este es el caso del que vamos a ocuparnos a continuación bajo el punto de vista técnico, siendo uno de los más interesantes por el número de edificios incluidos en los niveles de protección estructural y ambiental a los que puede afectar.

\subsection{VACIADO DEL EDIFICIO}

El vaciado o demolición total del interior del edificio conservando la fachada, comprende las siguientes operaciones:

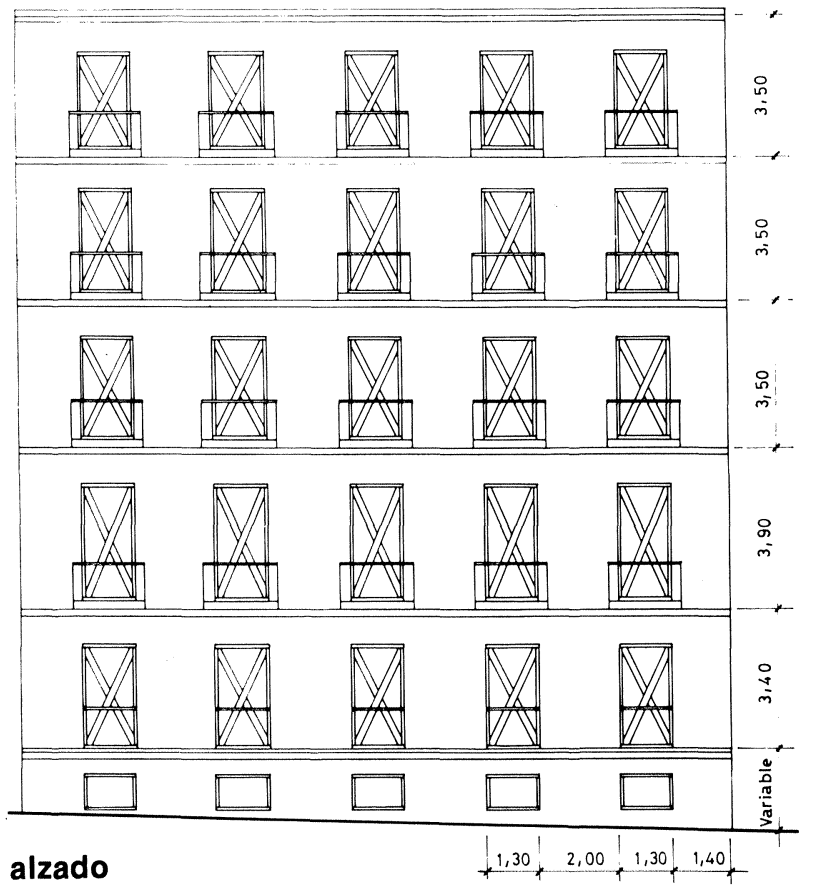

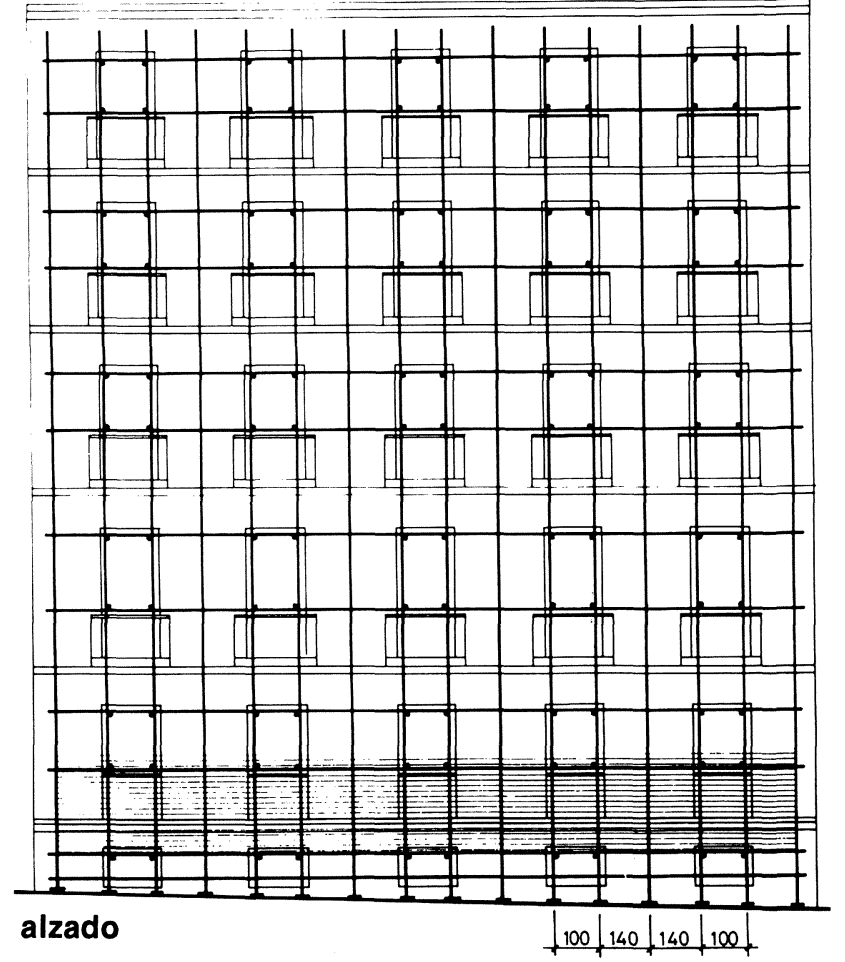

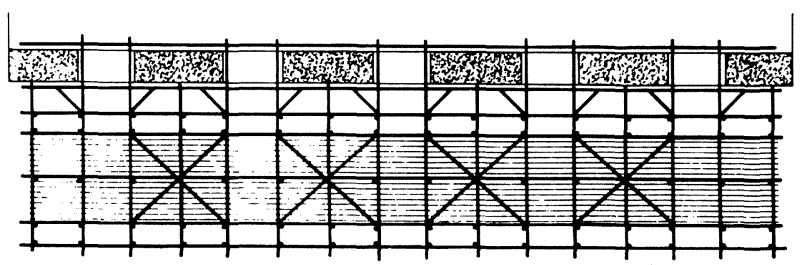

planta

1. ${ }^{a}$ Reconocimiento de la estructura del edificio, en especial del muro de fachada y forjados que cargan sobre él.

2. ${ }^{\text {a }}$ Recercado de huecos y arriostramiento con aspas, previo desmontaje de la carpinteria exterior.

3. ${ }^{\text {a }}$ Demolición de tabiquería, calado de forjados y demolición de elementos en la primera crujía que puedan entorpecer el apuntalamiento.

4. ${ }^{\text {a }}$ Apuntalamiento exterior del muro y arriostramiento a través de los huecos contra desplazamientos horizontales o desplomes.

5. ${ }^{a}$ Demolición total del interior y excavación del solar, en caso de hacer sótanos.

\subsection{PRECAUCIONES}

Antes de proceder a la demolición total del interior del edificio, deben tomarse ciertas precauciones:

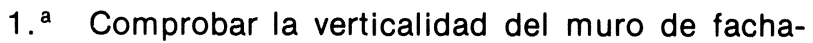
da y medir su posible desplome. 


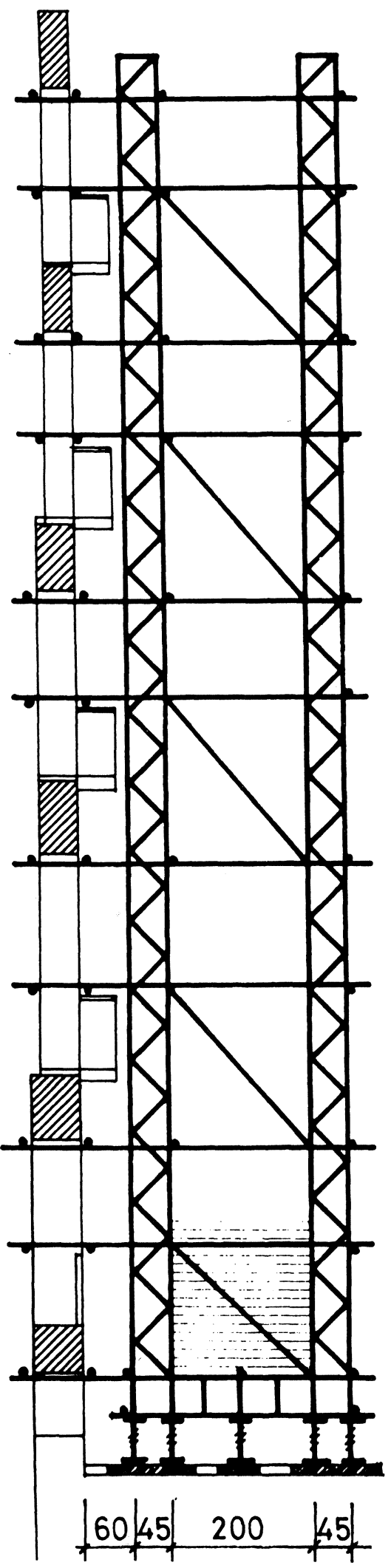

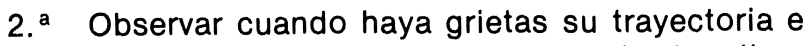
importancia para deducir, a partir de ellas, los movimientos a que ha estado sometido el muro de fachada, especialmente si hay grietas inclinadas que parten de los ángulos
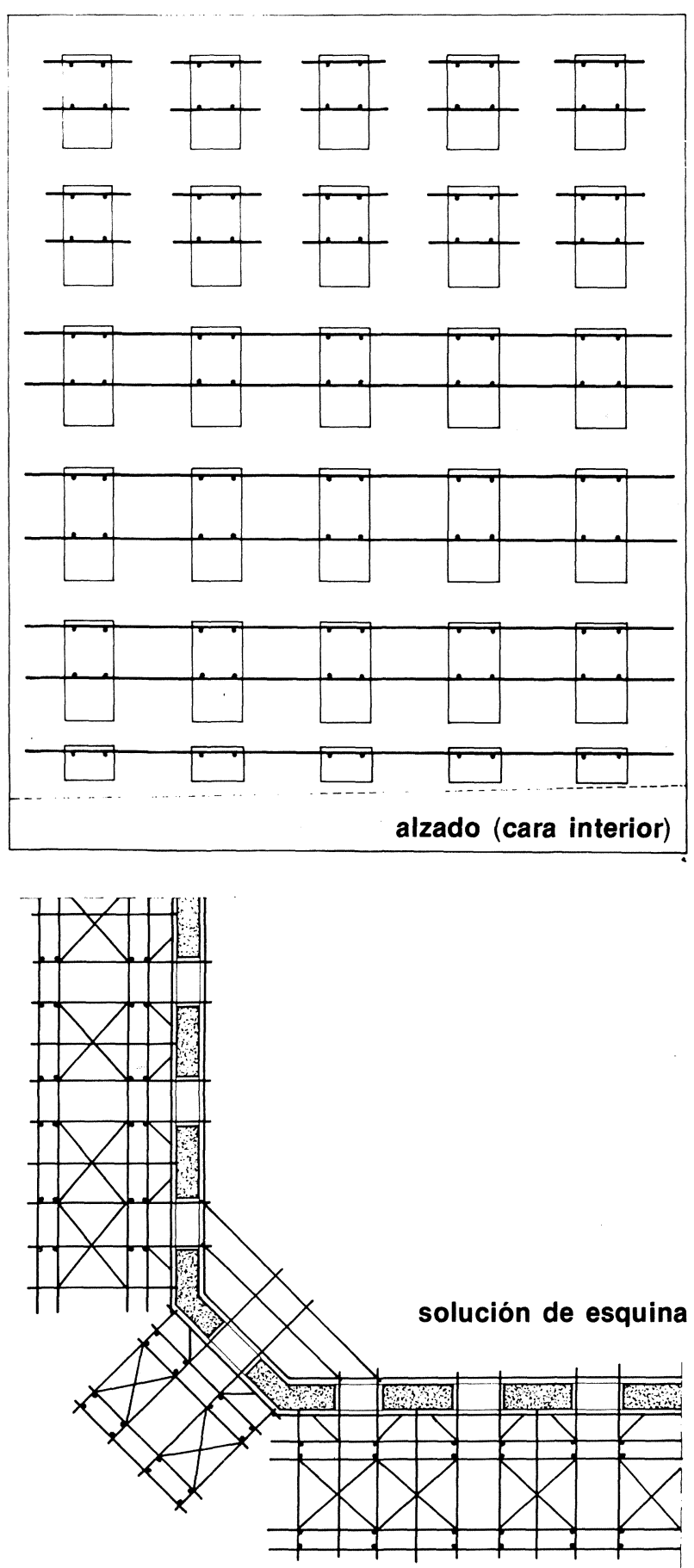

de los huecos, así como deformación angular de los mismos, que indicarán la presencia y localización de los asientos diferenciales.

3. ${ }^{a}$ Comprobar el estado de la cimentación y examinar el arranque del muro en planta baja, para detectar posibles humedades y sintomas de descomposición de las fábricas, sobre todo por su cara interior.

4. ${ }^{a}$ Antes de colocar el apuntalamiento exterior, examinar la acera y asegurarse de si existen, o no, oquedades o pequeños socavones bajo la misma. 
Detectar el posible paso de conducciones de agua, gas, electricidad, o cualquier galería o acometida subterránea, para adoptar las medidas que procedan.

5. ${ }^{\text {a }}$ Solicitar de las Compañias suministradoras la retirada de cables, palomillas, lineas de teléfono, etc. que puedan obstaculizar los trabajos.

\subsection{MEDIDAS DE SEGURIDAD}

Dentro de las medidas de seguridad a adoptar para garantizar la estabilidad del muro de fachada, entre las que se incluye el propio apeo y arriostramiento del mismo, consideramos las siguientes:

1. ${ }^{a} \quad$ El recercado de huecos se hará con tablones de madera escuadrada y su arriostramiento con cruces de San Andrés, con objeto de proporcionar una mayor rigidez frente a la deformación y dar continuidad al muro. A ser posible deberán mantenerse los cercos de la carpintería.

2. ${ }^{\text {a }}$ Al hacer la demolición de forjados no se deben extraer las viguetas y menos aún estando enteras para evitar el efecto de palanca sobre el muro que podria degollarlo, siendo preferible cortar las cabezas con sierra. Tanto las cabezas de viguetas como el durmiente de apoyo en el muro, no deben sacarse hasta el momento de colocar el nuevo forjado, actuando planta por planta.

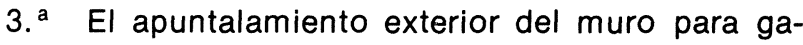
rantizar su estabilidad y el arriostramiento horizontal contra desplazamiento, y contra vuelco, deberá hacerse de acuerdo con las observaciones de la fachada y demás circunstancias indicadas en el apartado anterior sobre medidas de precaución.

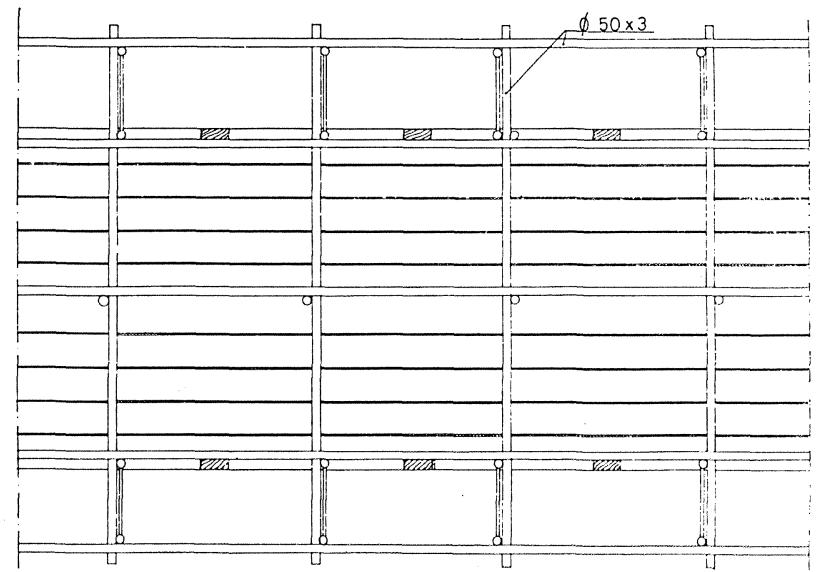

planta
4. ${ }^{a}$ Teniendo en cuenta que el interior del solar debe quedar lo más libre posible, tanto sí se va a excavar sótano como si no, todo el apeo deberá hacerse por el exterior del muro, y por lo tanto para garantizar la estabilidad de una estructura tan ligera deberá disponerse un contrapeso o lastre, que puede ser un cajón formado con tablas, relleno de arena o grava.

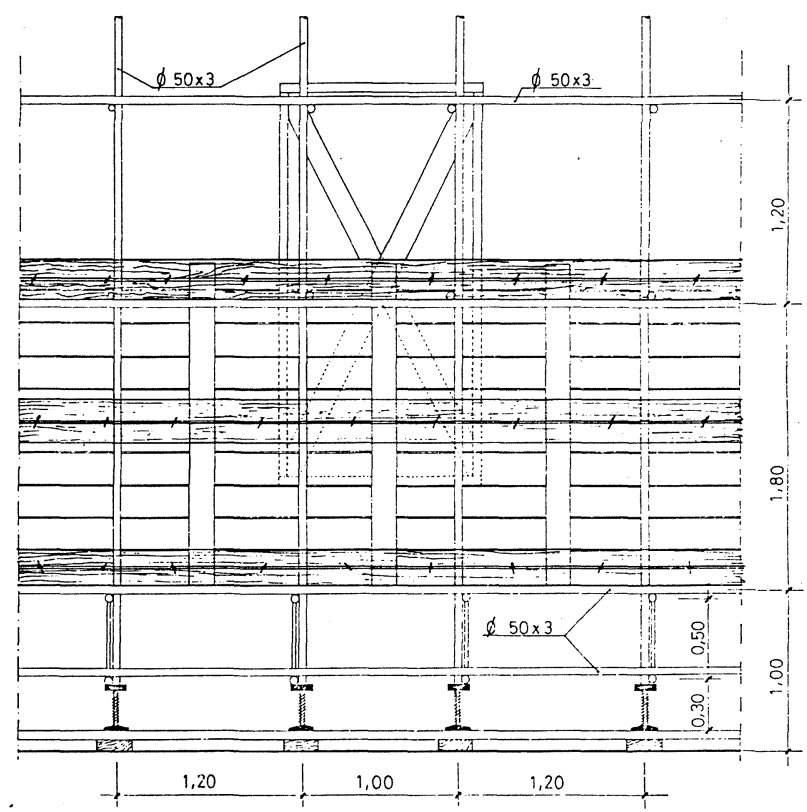

alzado

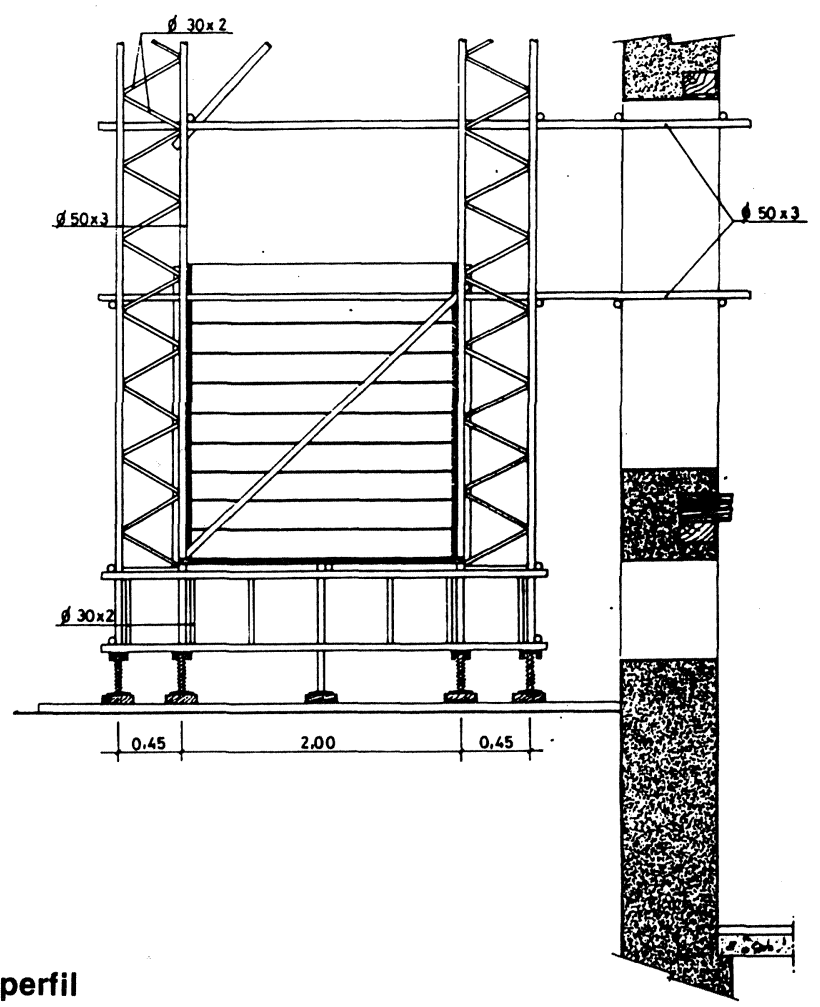

http://informesdelaconstruccion.revistas.csic.es 


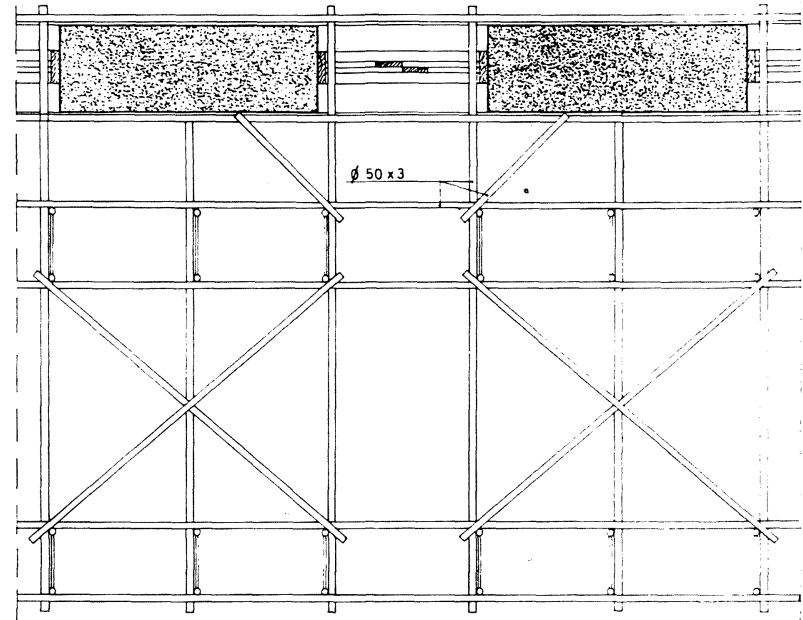

planta (nivel intermedio)

5. ${ }^{\text {a }}$ Durante la excavación del terreno deberán tomarse precauciones para evitar descalces $y$ giros de la cimentación del muro, que podrian provocar su derrumbamiento.

Es necesario pues, garantizar la estabilidad general del talud de tierras, actuando por bataches y construyendo el muro de contención por puntos. En caso necesario y según la naturaleza del terreno, deberá acodalarse la cabeza del muro contra el resto de la estructura previamente construida o apuntalar con tornapuntas. Puede ser interesante construir una pantalla antes de vaciar.

\subsection{APUNTALAMIENTO Y SUJECION DEL MURO DE FACHADA}

De los distintos sistemas de apuntalamiento, el más indicado en este caso es el de estructura metalica a base de tubos de acero unidos con bridas articuladas.

Las estructuras tubulares, que inicialmente sólo se utilizaban como estructuras secundarias para andamiajes y torres auxiliares en la construcción por su rapidez de montaje, hoy dia se emplean cada vez con más frecuencia en apeos y apuntalamientos exteriores, por su ligereza de peso con la ventaja de la recuperación total de todos sus elementos.

Es la solución más adecuada para el aseguramiento de fachadas, asi como para acodalar entre si muros de medianeria, ya que tanto las alturas como las distancias que se pueden alcanzar con este tipo de estructuras es considerable, con un peso propio relativamente bajo.

Además, permiten el acoplamiento y utilización de husillos para aproximar y poner en carga la estructura, lo cual tiene considerables ventajas. Es compatible con otros elementos, como la madera, para repartir la carga sobre el suelo o sobre las paredes a través de tablones a fin de evitar punzonamientos, pudiendo clavarse 0 atornillarse a la madera las placas de reparto.

Los elementos que componen este tipo de estructura pueden ser simples o compuestos.

Los elementos simples son sencillamente tubos comerciales de distintos diámetros y gruesos según las cargas que tengan que soportar.

Los elementos compuestos están constituidos por dos, tres o cuatro tubos unidos por barras también tubulares de menor diámetro formando triangulación.

Estos elementos se utilizan cuando es necesaria una gran inercia para reducir el pandeo lateral, frente a grandes cargas y con grandes luces.

Los elementos simples pueden mejorar su capacidad de carga, si se reducen las luces, aumentando el número de arriostramientos.

La gran ventaja de estas estructuras es su facilidad para el arriostramiento entre los distintos elementos, y en tres dimensiones hasta formar una verdadera malla espacial, cuya retícula puede ser del tamaño que se desee.
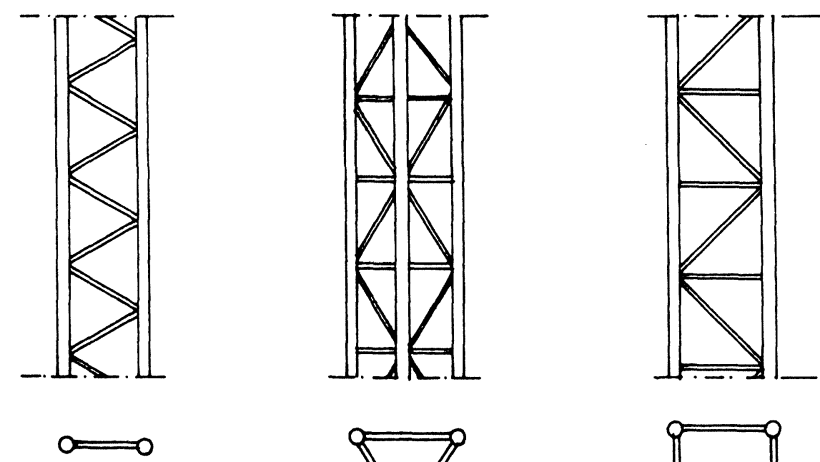

0
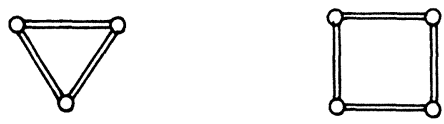

Las dimensiones más usuales y características geométricas de sección $A$ y radio de giro $i$, se dan en la tabla A-1 (página siguiente), tomadas de la norma básica M.V. 108-1976 "PERFILES HUECOS DE ACERO PARA ESTRUCTURAS DE EDIFICACION".

Dicha tabla se ha completado con la carga $N$, en toneladas, que pueden resistir a compresión simple para longitudes libres de pandeo de $1,00 \mathrm{~m}$ a $2,50 \mathrm{~m}$.

Todos los perfiles huecos llevan marcadas las siglas de la fábrica y la de la clase de acero que es la A 42 b. 
TABLA A-1

Carga $\mathbf{N}$ en toneladas, para una longitud $\mathrm{L} \mathbf{m}$

\begin{tabular}{|c|c|c|c|c|c|c|c|c|c|}
\hline $\begin{array}{c}\text { PERFIL } \\
\varnothing\end{array}$ & $\underset{\mathrm{cm}^{2}}{\mathrm{~A}}$ & $\begin{array}{c}\mathbf{i} \\
\mathrm{cm}\end{array}$ & 1,00 & 1,25 & 1,50 & 1,75 & 2,00 & 2,25 & 2,50 \\
\hline 40,2 & 2,39 & 1,35 & 2,62 & 1,91 & 1,31 & 0,96 & 0,74 & & \\
\hline 40,3 & 3,49 & 1,31 & 3,72 & 2,67 & 1,78 & 1,31 & 1,00 & & \\
\hline 40.4 & 4,52 & 1,28 & 4,70 & 3,22 & 2,23 & 1,61 & 1,26 & & \\
\hline 45.2 & 2,70 & 1,52 & 3,22 & 2,65 & 1,88 & 1,38 & 1,05 & 0,83 & \\
\hline 45.3 & 3,96 & 1,49 & 4,69 & 3,75 & 2,63 & 1,95 & 1,49 & 1,17 & \\
\hline 45.4 & 5,15 & 1,45 & 5,97 & 4,73 & 3,28 & 2,38 & 1,83 & 1,45 & \\
\hline 50.2 & 3,02 & 1,69 & 3,86 & 3,31 & 2,62 & 1,89 & 1,47 & 1,15 & 0,93 \\
\hline 50.3 & 4,43 & 1,66 & 5,62 & 4,79 & 3,77 & 2,71 & 2,08 & 1,62 & 1,31 \\
\hline 50.4 & 5,78 & 1,63 & 7,28 & 6,08 & 4,74 & 3,41 & 2,58 & 2,05 & 1,67 \\
\hline 60.2 & 3,64 & 2,05 & 5,02 & 4,58 & 4,04 & 3,40 & 2,60 & 2,03 & 1,65 \\
\hline 60.3 & 5,37 & 2,01 & 7,34 & 6,66 & 5,80 & 4,82 & 3,64 & 2,89 & 2,36 \\
\hline 60.4 & 7,04 & 1,98 & 9,54 & 8,66 & 7,22 & 6,22 & 4,67 & 3,67 & 3,00 \\
\hline 75.2 & 4,58 & 2,58 & 6,66 & 6,37 & 5,91 & 5,39 & 4,76 & 4,11 & 3,34 \\
\hline 75.3 & 6,78 & 2,54 & 9,86 & 9,35 & 8,68 & 7,86 & 6,95 & 5,89 & 4,84 \\
\hline 75.4 & 8,92 & 2,51 & 12,97 & 12,20 & 10,32 & 10,26 & 8,97 & 7,59 & 6,05 \\
\hline 90.3 & 8,19 & 3,07 & 12,36 & 11,80 & 11,29 & 10,65 & 9,92 & 9,10 & 8,14 \\
\hline 90.4 & 10,80 & 3,04 & 16,15 & 15,56 & 14,89 & 13,93 & 12,89 & 11,83 & 10,60 \\
\hline 90.5 & 13,40 & 3,01 & 20,03 & 19,31 & 18,32 & 17,29 & 16,00 & 14,48 & 13,15 \\
\hline
\end{tabular}

Según la norma MV 102-1975, el límite elástico de esta clase de acero, para espesores de hasta $16 \mathrm{~mm}$ es: $L E=2.600 \mathrm{~kg} / \mathrm{cm}^{2}$.

Para este limite elástico y con el tipo de carga I (con carga más sobrecarga vertical), el prontuario de Altos Hornos considera una tensión admisible de $\sigma_{\text {adm }}=1.730 \mathrm{~kg} / \mathrm{cm}^{2}$, lo cual supone un coeficiente de seguridad de 1,5.

Sin embargo, hemos considerado más prudente utilizar como valor de la tensión admisible $\sigma_{\text {adm }}=1.600 \mathrm{~kg} / \mathrm{cm}^{2}$. la cual proporciona un coeficiente de seguridad de 1,63.

Asi pues, la carga $\mathrm{N}$ que puede resistir cada perfil a compresión simple, viene dada en función de la sección $A$, del coeficiente de pandeo $\omega$ y de la tensión admisible $\sigma_{\text {adm, por la fórmula: }}$

$$
\mathrm{N}=\frac{\mathrm{A}}{\omega} \cdot \sigma_{\mathrm{adm}}=\frac{\mathrm{A}}{\omega} \cdot 1,6 \mathrm{t} .
$$

(expresando A en $\mathrm{cm}^{2}$ y $\sigma_{\mathrm{adm}}=1,6 \mathrm{t} / \mathrm{cm}^{2}$ ).

De la simple observación de la tabla A-1 se deduce que la capacidad de carga disminuye rápidamente con el aumento de longitud, dada la notable influencia de la esbeltez que en estos elementos es grande.
Por ello es recomendable no pasar de longitudes libres de pandeo superiores a $2,00 \mathrm{~m}$ para aprovechar la resistencia de la sección del tubo, siendo preferible acortar las longitudes de pandeo con arriostramientos más próximos, a utilizar perfiles de mayor sección que darian mayor peso y por lo tanto serían más costosos.

La carga que pueden resistir a tracción será:

$$
\mathrm{N}=\sigma_{\mathrm{adm}} \cdot \mathrm{A}=1,6 \mathrm{~A} \text { t. } \quad\left(A \text { en } \mathrm{cm}^{2}\right)
$$

\section{5. - CALCULO DE LA ESTRUCTURA DE APEO}

El cálculo de los esfuerzos en las barras depende fundamentalmente de las acciones horizontales de viento y más aleatoriamente de las que se deriven de los desplazamientos por giro o desplome del muro, las cuales hay que prever también aunque no siempre lleguen a producirse.

Se supone que el muro resiste toda la carga vertical, Pv debida a su propio peso, máxime considerando que se va a descargar del peso de los forjados y que todos los huecos han sido previamente recercados y arriostrados diagonalmente. Si bien al suprimir los forjados aumenta la esbeltez a efectos de pandeo, sin embargo el arriostramiento lateral con la estructura tubular va a ser mucho mayor. El problema queda reducido, pues, al de la estabilidad general al vuelco. 
Las acciones de viento no son muy importantes, teniendo en cuenta que el edificio dentro de la ciudad está en situación protegida y que la altura no es considerable. Por otra parte al estar todos los huecos abiertos, se reduce bastante la resistencia al viento. La resultante de las acciones de viento estará aplicada en la mitad de la altura.

El posible desplome del muro se traducirá en un momento de vuelco que se obtendrá en función de la excentricidad en la base del mismo.

$$
M=P v \cdot e
$$

Pueden obtenerse los momentos parciales en cada planta, de los que se deducen fácilmente las acciones horizontales.

Como ejemplo, veamos las acciones parciales en cada planta en el caso de cuatro plantas de igual altura $=h$.

A partir de las cargas verticales $\mathrm{Pv}$ se deducen fácilmente los momentos $\mathrm{M}$ y las acciones horizontales $\mathrm{Ph}$ en cada planta.

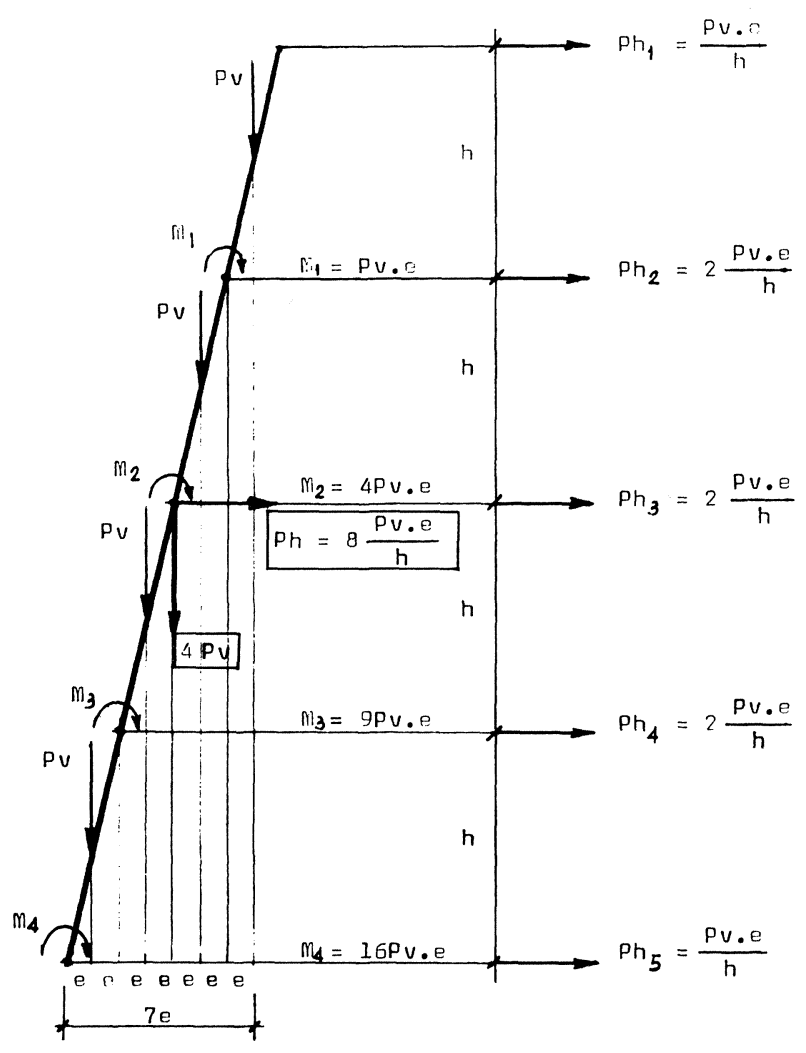

Resultante de cargas verticales $=4 \mathrm{Pv}$

Resultante de cargas horizontales $=8 \frac{\mathrm{Pv}}{\mathrm{h}} \cdot \underline{\mathrm{e}}$

Momento de vuelco $\mathrm{Mv}=16 \mathrm{Pv}$.e

En cuanto al sismo, sólo habrá que tenerlo en cuenta en zonas de alta sismicidad, cuyo grado en la escala de Mercalli sea superior a VI.
Considerando la actuación simultánea de viento y giro o desplome, puede utilizarse una fórmula simplificada mediante la introducción de un coeficiente de empuje $\mathrm{K}$, que multiplicado por la carga vertical del muro nos dará la componente horizontal resultante de todas las acciones horizontales.

$$
\mathrm{Ph}=\mathrm{K} \cdot \mathrm{PV}
$$

la cual corresponde a una ley triangular de presiones cuya resultante estará aplicada por tanto a un tercio de la altura.

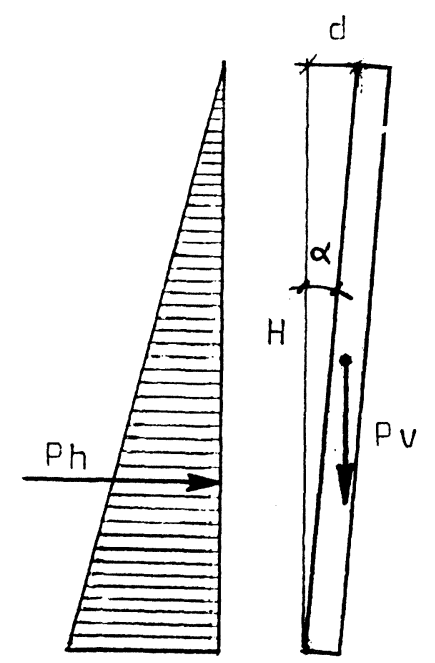

Giro o inclinación $=\alpha$

Desplome $=\mathrm{d}$

$$
\operatorname{tg} \alpha=\frac{\mathrm{d}}{\mathrm{H}}
$$

Valor estimativo de $\mathrm{K}$ :

$$
\begin{array}{ll}
\text { Para } \quad \operatorname{tg} \alpha<1 / 250 & \mathrm{~K}=0,10 \\
\text { Para } 1 / 250 \leqslant \operatorname{tg} \alpha<1 / 150 & \mathrm{~K}=0,15 \\
\text { Para } 1 / 150 \leqslant \operatorname{tg} \alpha & \mathrm{K}=0,20
\end{array}
$$

El sentido de esta fuerza horizontal normalmente será hacia el interior del solar, dada la antigua costumbre de construir los muros de fachada a favor de obra, y dadas las alteraciones que pueden producirse en el terreno interior y las acciones del viento.

Por consiguiente las barras horizontales e inclinadas según la disposición que se representa en los planos, trabajarán a tracción. Las barras verticales más próximas a la fachada trabajarian a compresión y las más alejadas, a tracción.

Con las cargas horizontales correspondientes a cada planta aplicadas en los nudos de la estructura tubular, pueden determinarse los esfuerzos en las barras. Generalmente bastará con una comprobación de las barras más solicitadas.

Por último hay que comprobar la estabilidad general al vuelco y calcular la carga del contrapeso, 
para lo cual se toman momentos con respecto al pie del muro.

Aplicando al momento de vuelco un coeficiente de seguridad (generalmente bastará con 1,5) obtenemos el momento estabilizador necesario

$$
M e=1,5 \times M v
$$

y dividiendo por la distancia entre ejes de contrapeso y muro, se obtiene la carga del contrapeso. Bastará dividir por el peso especifico del material que se emplee como lastre para tener el volumen.
Todos los cálculos se harán por unidad de longitud de fachada, tomando como unidad $1,00 \mathrm{~m}$.

De acuerdo con lo expuesto anteriormente, se desarrollan a continuación unos ejemplos de cálculo del contrapeso, considerando dos casos:

Caso I Muro perfectamente aplomado y solicitado exclusivamente por acciones de viento.

Caso II Muro con un desplome de $0,10 \mathrm{~m}$ hacia el interior y efecto de giro por descalce de la cimentación, además de la acción del viento. Método simplificado del coeficiente de empuje.

\section{EJEMPLOS DE CALCULO DE CONTRAPESO}

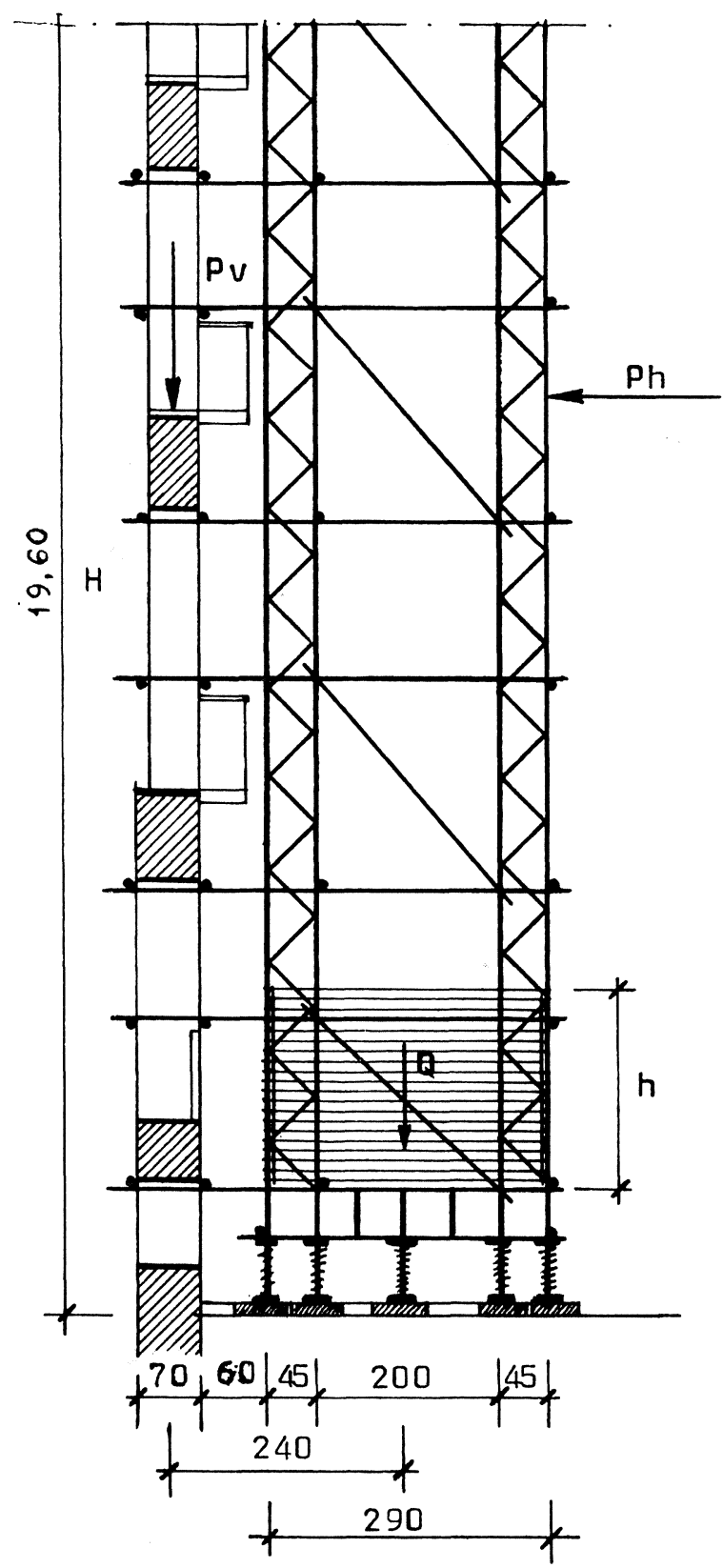

\section{CASO I: ACCION DE VIENTO}

Presión dinámica $w=75 \mathrm{~kg} / \mathrm{m}^{2}$.

Coeficiente eólice $c=1,2$ (presión + succión)

Acción de viento $p=1,2 \times 75=90 \mathrm{~kg} / \mathrm{m}^{2}$.

Deducción $24 \%$ de huecos.

Acción neta $\mathrm{p}=0,76 \times 90=68,4 \mathrm{~kg} / \mathrm{m}^{2}$.

Empuje total $\mathrm{Ph}=68,4 \times 19,60=1.340,6 \mathrm{~kg}$.

$M v=1.340,6 \times \frac{19,60}{2}=13.138 \mathrm{mkg}$.

Coeficiente de seguridad $F=1,5$.

$\mathrm{Me}=13.138 \times 1,5=19.707 \mathrm{mkg}$.

Lastre $Q=19.707 / 2,40=8.211 \mathrm{~kg}$.

Peso específico relleno $\gamma=1.700 \mathrm{~kg} / \mathrm{m}^{3}$.

Volumen $\mathrm{V}=8.211 / 1.700=4,83 \mathrm{~m}^{3}$

Altura del contrapeso $h=4,83 / 2,90=1,66 \mathrm{~m}$.

\section{CASO II: VIENTO + CARGA EXCENTRICA}

Desplome $\mathrm{d}=0,10 \mathrm{~m}$.

Altura $\mathrm{H}=19,60 \mathrm{~m}$.

$\operatorname{tg} \alpha=0,10 / 19,60=1 / 196$.

Coeficiente de empuje $\mathrm{K}=0,15$.

$\mathrm{Pv}=19,60 \times 0,50 \times 1.800=17.640 \mathrm{~kg}$

(se ha tomado un espesor medio $0,50 \mathrm{~m}$.).

$\mathrm{Ph}=17.640 \times 0,15=2.646 \mathrm{~kg}$.

$M v=2.646 \times 19,60 / 3=17.287 \mathrm{mkg}$.

$\mathrm{Me}=17.287 \times 1,5=25.930 \mathrm{mkg}$.

Lastre $Q=25.930 / 2,40=10.805 \mathrm{~kg}$.

Volumen $\mathrm{V}=10.805 / 1.700=6,35 \mathrm{~m}^{3}$.

Altura contrapeso $h=6,35 / 2,90=2,19 \mathrm{~m}$.

Conviene señalar que la instalación y cálculo de la estructura de apeo, así como del contrapeso, estarán condicionados en determinados casos a la anchura de la calle o de la acera, incluso puede ocurrir que el contrapeso no sea necesario. Por 
tanto, el cálculo no debe hacerse de una manera rutinaria.

Hay que tener presente la posible circunstancia de que la fachada esté desplomada hacia el exterior, al menos de forma parcial, lo cual suele ir acompañado de bombeos en las plantas intermedias, con deformaciones a veces importantes producidas por pandeo. En este caso, conviene analizar las acciones horizontales que pueden producirse en ambos sentidos y considerar todas las hipótesis posibles con las combinaciones más desfavorables. La ausencia de viento es un supuesto que se da normalmente, y que si coincide con el desplome de la fachada hacia el exterior, puede producirse el vuelco de la misma en ese sentido, encontrándonos en el caso frecuente de apeo con tornapuntas exteriores trabajando exclusivamente a compresión. Aquí sobraría el contrapeso, limitándonos a apoyar los tornapuntas a través de durmientes de reparto para transmitir las cargas al suelo.

Pero así como en un edificio completo el desplome o bombeo hacia el exterior de la fachada o de un muro medianero al descubierto (e incluso la inclinación de todo el edificio), es lo que con frecuencia demanda el apeo con tornapuntas, siendo improbable un cambio de sentido en el movimiento de tales elementos, aun cuando actúe la presión del viento, por impedirlo la propia estructura del edificio, en cambio, en un muro exento que inicialmente tenga un ligero desplome hacia el exterior cabe la probabilidad de un cambio de signo por acción del viento, socavación interior,
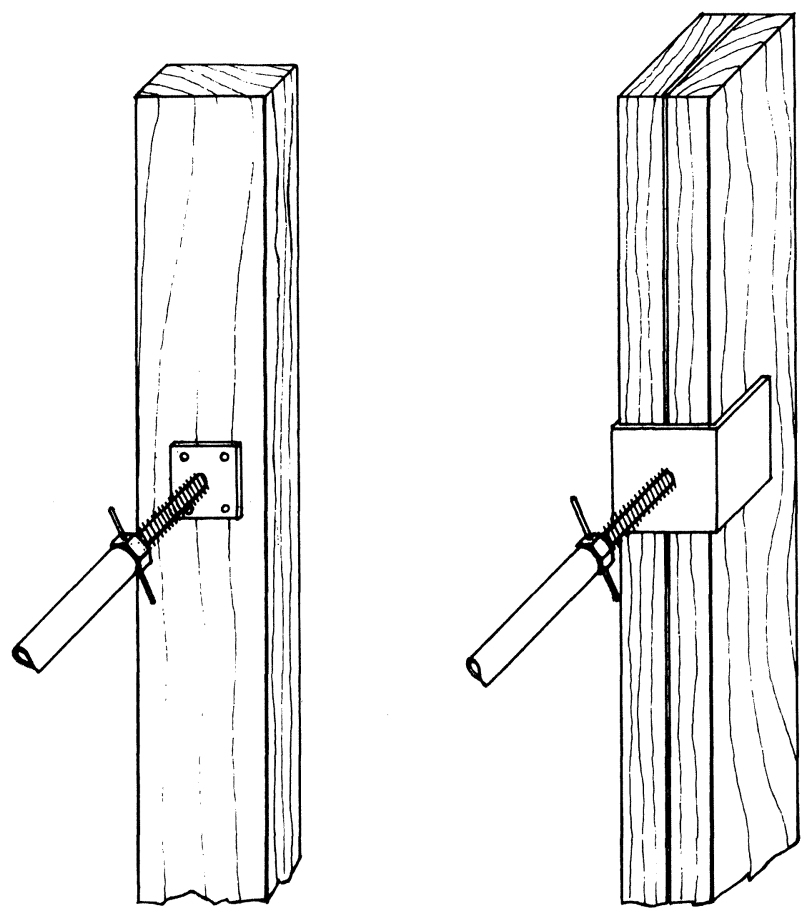

etcétera. $Y$ por tanto habrá que asegurarse contra un posible levantamiento de la estructura de apeo, previendo el contrarresto del mismo mediante lastre.

Para el reparto de cargas sobre los muros, cuando hay que acodalar o tornapuntar, se emplean tablones de madera de escuadría $20 \times 7 \mathrm{~cm}$ colocados por tabla 0 por canto según la rigidez necesaria. En el primer caso los husillos terminan en una placa cuadrada o circular que aprieta sobre el tablón. En el segundo caso los husillos terminan en una horquilla de chapa de $15 \times 15 \mathrm{~cm}$ que abraza a un doble tablón colocado de canto.

\section{NORMATIVA A APLICAR}

Entre las normas españolas que tienen relación con la estructura tubular de apeo que hemos expuesto, figuran las siguientes:

MV 101 - 1962 "ACCIONES EN LA EDIFICA-

MV 102 - 1975 "ACERO LAMINADO PARA ESTRUCTURAS DE EDIFICACION"
MV 106 - 1968 "TORNILLOS ORDINARIOS Y CALIBRADOS PARA ESTRUC- TURAS DE ACERO"
MV 107 - 1968 "TORNILLOS DE ALTA RESIS- TENCIA PARA ESTRUCTURAS DE ACERO»
MV 108 - 1976 "PERFILES HUECOS DE ACERO PARA ESTRUCTURAS DE EDI- FICACION"
MV 109 - 1979 "PERFILES CONFORMADOS DE ACERO PARA ESTRUCTURAS DE EDIFICACION"

\section{COSTES DEL APEO}

Aunque las casas comerciales estudiarán en cada caso el presupuesto del apeo según sus dimensiones, número de elementos, secciones de los tubos, etc., se dan a título orientativo los precios de montaje y desmontaje para diferentes alturas y con un fondo de 2,50 a $3,00 \mathrm{~m}$, sin incluir la caja del contrapeso. (Ver cuadro pág. siguiente). 


\begin{tabular}{ccc}
$\begin{array}{c}\text { N. } \\
\text { PLANTAS }\end{array}$ & $\begin{array}{c}\text { ALTURA } \\
\mathbf{m} .\end{array}$ & $\begin{array}{c}\text { MONTAJE } \\
\text { DESMONTAJE } \\
\text { pts / } \mathbf{m}^{2}\end{array}$ \\
\hline & & \\
1 & 4,00 & $1.915,-$ \\
2 & 7,00 & $2.020,-$ \\
3 & 10,00 & $2.145,-$ \\
4 & 13,00 & $2.325,-$ \\
5 & 16,00 & $2.445,-$ \\
6 & 19,00 & $2.570,-$ \\
7 & 22,00 & $2.700,-$ \\
8 & 25,00 & $2.830,-$
\end{tabular}

Hay que tener en cuenta, además, el coste del alquiler diario, incluidos domingos y dias festivos, el cual depende de la densidad o número de elementos que entran por metro cuadrado. Puede oscilar entre 15,00 y 19,50 ptas/m2 por lo que para una estimación aproximada podemos tomar un precio medio actual de:

$$
\text { Alquiler diario }=17,50 \mathrm{ptas} / \mathrm{m}^{2}
$$

\section{publicaciones del I.E.T.c.c.}

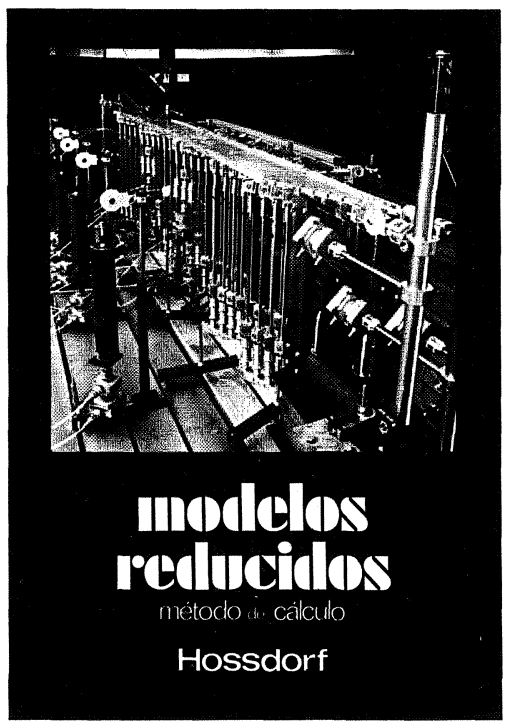

Modelos reducidos. Método de cálculo

H. Hossdorf, Ingeniero Civil

La técnica de los ensayos en modelos reducidos de estructuras sufre hoy dia una decisiva metamorfosis.
Hasta hace poco era un medio más bien de artesaHasta hace poco era un medio más bien de artesania, que no siempre era tomado en serio por los miento resistente de las estructuras complejas y al que se acudió las más de las veces, como a un último remedio debido a sus indiscutibles insuficiencias. Sin embargo, en poco tiempo y gracias a su conexión con los ordenadores digitales, se ha transformado en un instrumento cientificamente valioso, que no puede quedar a un lado en la práctica diaria del Ingeniero Proyectista.

Un volumen encuadernado en cartoné plastificado con lomo de tela, de $17 \times 24 \mathrm{~cm}$, compuesto de 250 páginas, 158 figuras y fotografias.

Precios: 1.800 ptas.; $\$$ USA 26.00

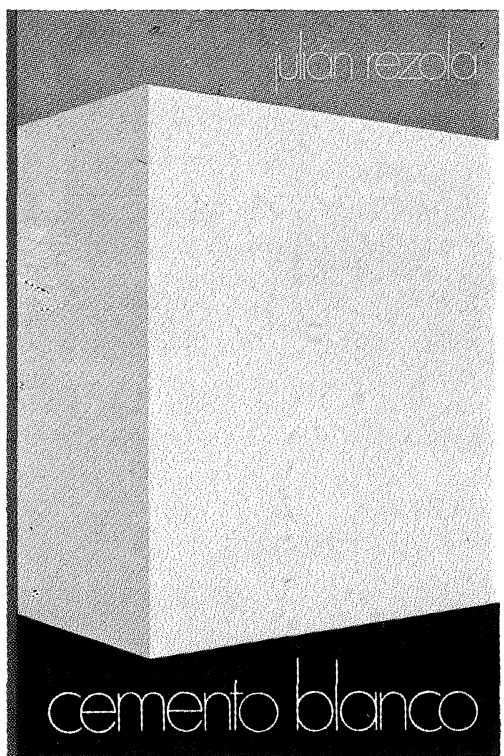

\section{Cemento blanco}

Julián Rezola

Ingeniero Quimico Dipl. I. Q. S.

Sabido es que existe una extensa y documentada bibliografia sobre el cemento gris: en cambio, no puede decirse lo mismo acerca del cemento portland blanco, ya que los escritos existentes se refieren tan sólo a algunas peculiaridades que le distinguen de aquél.

El autor nos ofrece sus profundos conocimientos y su larga experiencia tanto en laboratorio como

La parte descriptiva del libro se complementa con gráficos, diagramas y fotografias de gran utilidad, destinados a conseguir la aplicación apropiada de este aglomerante.

Un volumen encuadernado en cartoné policerado, de $17,4 \times 24,3 \mathrm{~cm}$, compuesto de 395 páginas, numerosas figuras, tablas y ábacos.

Precios: España, 1.700 ptas.: extranjero, $\$ 34$

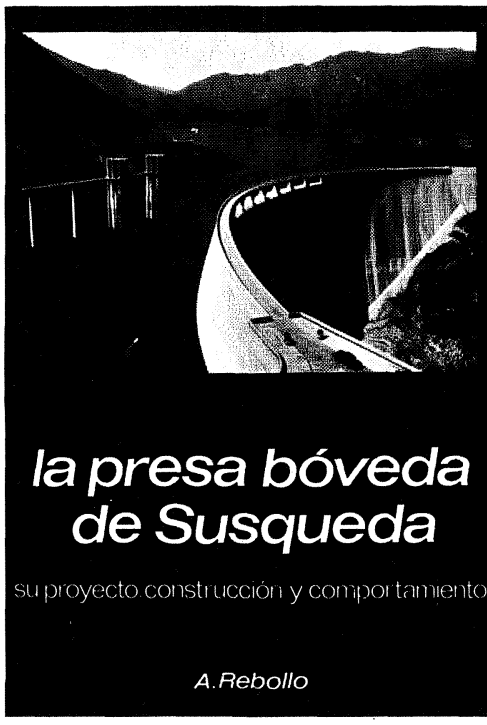

La presa bóveda de Susqueda

A. Rebollo,

Dr. Ingeniero de Caminos

El esfuerzo del constructor de presas se sitúa por su pretensión de perennidad, a contracorriente de las pendencis de la civización actual, caracterizada por lo tungible. Pueden evocarse las 10.000 grandes.presas en funcionamiento o en construcción que están gerontológicos para mantener y perfeccionar su prio perennidad. En riesgos ecologicos $y$, veces, aumentan con el enveiecimiento, a gelonitio que las presas es todo un emplazo. La accion adela de de Arturo Rebollo en este trreno mica un camino a seguir para todos los que aman su propia camino la devoción paternal que el ha puesto en Susqueda.

Un volumen encuadernado en cartoné plastificado con lomo de tela, de $18 \times 24,5 \mathrm{~cm}$, compuesto de 408 páginas, 330 figuras $y$ fotografias $y 39$ tablas.

Precios: 1.700 ptas.; extranjero, \$ USA 24.00. 